ORIGINAL ARTICLE

\title{
An evaluation of a "best practices" musculoskeletal injury prevention program in nursing homes
}

\author{
J W Collins, L Wolf, J Bell, B Evanoff
}

Injury Prevention 2004;10:206-211. doi: 10.1136/ip.2004.005595

See end of article for authors' affiliations

Correspondence to: Correspondence to:
Dr James W Collins, Centers for Disease Control and Prevention National Institute for Occupational Safety and Health, Division of Safety Research, 1095 Willowdale Road, Mail Stop 1811, Morgantown WV 26505, USA; JCollins1@cdc.gov

\begin{abstract}
Objective: To conduct an intervention trial of a "best practices" musculoskeletal injury prevention program designed to safely lift physically dependent nursing home residents.

Design: A pre-post intervention trial and cost benefit analysis at six nursing homes from January 1995 through December 2000. The intervention was established in January 1998 and injury rates, injury related costs and benefits, and severity are compared for 36 months pre-intervention and 36 months postintervention.

Participants: A dynamic cohort of all nursing staff $(n=1728)$ in six nursing homes during a six year study period.

Intervention: "Best practices" musculoskeletal injury prevention program consisting of mechanical lifts and repositioning aids, a zero lift policy, and employee training on lift usage.

Main outcome measures: Injury incidence rates, workers' compensation costs, lost work day injury rates, restricted work day rates, and resident assaults on caregivers, annually from January 1995 through December 2000.

Results: There was a significant reduction in resident handling injury incidence, workers' compensation costs, and lost workday injuries after the intervention. Adjusted rate ratios were 0.39 (95\% confidence interval (Cl) 0.29 to 0.55 ) for workers' compensation claims, 0.54 (95\% Cl 0.40 to 0.73 ) for Occupational Safety and Health Administration (OSHA) 200 logs, and $0.65(95 \% \mathrm{Cl} 0.50$ to 0.86$)$ for first reports of employee injury. The initial investment of $\$ 158556$ for lifting equipment and worker training was recovered in less than three years based on post-intervention savings of $\$ 55000$ annually in workers' compensation costs. The rate of post-intervention assaults on caregivers during resident transfers was down $72 \%, 50 \%$, and $30 \%$ based on workers' compensation, OSHA, and first reports of injury data, respectively.

Conclusions: The "best practices" prevention program significantly reduced injuries for full time and part time nurses in all age groups, all lengths of experience in all study sites.
\end{abstract}

t has been stated that "The adult human form is an awkward burden to lift or carry. Weighing up to 200 pounds or more, it has no handles, it is not rigid, and is susceptible to severe damage if mishandled or dropped. When lying in a bed, a patient is placed inconveniently for lifting, and the weight and placement of such a load would be tolerated by few industrial workers". ${ }^{1}$ This editorial was published almost 40 years ago and nurses continue to suffer a high prevalence of work related back pain and workers' compensation claims. ${ }^{2}{ }^{3}$ Employees in nursing and personal care homes suffer an estimated 200000 work related injuries and illnesses a year ${ }^{4}$ and within nursing, nursing aides and orderlies in long term care have the highest rates. Among female workers in the United States, nursing aides and orderlies suffer the highest prevalence (18.8\%) and report the most annual cases of work related back pain $(n=269000){ }^{2}$ Lifting "health care patients" is the leading source of injury. Factors which contribute to the difficulty of lifting and moving a long term care resident* include the size and weight of the resident, combativeness, propensity for the resident to fall, and $90 \%$ of the nursing staff moving physically dependent residents are female. ${ }^{4}$ Many of these transfers are performed in small resident bathrooms and rooms cluttered with medical equipment. The most physically demanding tasks in nursing homes performed by nursing personnel are transferring physically dependent residents to and from the toilet, in and out of beds and chairs, repositioning in bed, and transfers for bathing and weighing residents. ${ }^{5}$ A critical shortage in the nursing work force, ${ }^{6}$ coupled with the excessively high back injury rate, raises serious concerns about the capacity of the nursing workforce to care for our nation's expanding population, particularly the rapidly increasing number of older people.

As a precursor to the current study, a biomechanical laboratory study ${ }^{7}$ and psychophysical evaluation ${ }^{8}$ measured physical exposures associated with nine battery powered lifts and three manual methods for transferring physically dependent residents from a bed to a chair. Mechanical lifts were shown to reduce the back compressive forces on nursing personnel by an estimated $60 \%$, remove two thirds of the lifting activities per transfer, and increase the resident's perceptions of comfort and security as compared with being manually lifted. In light of the success of mechanical lifts demonstrated by laboratory studies and small field studies, the current field study was conducted to determine if an intervention consisting of mechanical equipment to lift physically dependent residents, training on the proper use of the lifts, a zero lift policy, and a pre-existing medical management program would reduce the rate and associated costs of resident handling injuries in a large population of nursing personnel in a real world setting. ${ }^{10}$

Abbreviations: $\mathrm{Cl}$, confidence interval; OSHA, Occupational Safety and Health Administration

*Patients in long term care facilities are called "residents". 


\section{METHODS}

\section{Study design}

A six year intervention trial evaluated the back injury prevention program in a dynamic cohort of nursing personnel. The intervention was implemented in six nursing homes, covering a total of 552 licensed beds and facilities ranged in size from 60 to 120 beds. The intervention was introduced in January 1998. Injury rates, costs, and lost and restricted workday rates were compared for the three year preintervention (1995-97) and three year post-intervention (1998-2000) periods.

\section{"Best practices" intervention}

Based on an evaluation of the scientific literature on safe resident handling and movement and public peer review of the research protocol by experts in patient handling, the key elements of a "best practices" intervention were determined to include mechanical lifting equipment and repositioning aids, worker training on the use of the lifts, a medical management program, and a written zero lift policy. Training was provided to all staff involved in the use and maintenance of the mechanical lifting equipment. A pre-existing medical management program, which provided medical care to injured workers and modified duty programs, was in place during both the pre-intervention and post-intervention periods. The providers of medical care did not change during the study period and no major changes in the policies and procedures of medical management were noted.

\section{Equipment interventions}

Three categories of resident handling equipment were implemented to prevent injuries associated with lifting and repositioning. Friction reducing sheets were used for repositioning residents in bed and two types of mechanical lifts were used, based on the resident's level of physical dependency. For residents who could not bear weight and required total assistance, a full body lift was used for transfers from bed to chair and chair to toilet, as well as to weigh residents, and to lift residents who had fallen to the floor. For residents with partial weight bearing capability, a second type of mechanical lift, referred to as a stand-up lift, was used to assist with high risk tasks such as toileting, bed to chair transfers, changing of incontinence briefs, and ambulation. Staff buy-in to participate in the prevention program were created by allowing the nursing home staff to evaluate and provide input on the selection of lifting equipment before implementation.

\section{Written zero lift policy \\ The "zero lift" policy provided written guidelines for assessing each resident's transferring needs and procedures for the safe handling and movement of residents. The term "zero lift" implied there should be no manual lifting of residents. However, there were residents who could be safely transferred with limited manual assistance and mechanical lifts were used when a resident could not be safely trans- ferred by any other means. The charge nurse was responsible for ensuring all transfers were done in accordance with the written policy, and the nursing home administrator had the final responsibility for enforcing the policy.}

\section{Training}

Initially, training consisted of 10-20 nursing staff receiving 30 minutes of knowledge based training and demonstration of the use of the lifting equipment by the trainers. It was determined that the initial training method did not adequately prepare nursing staff to use the lifting equipment on all residents. Subsequently, the training was refined to provide 45 minutes of additional skill based training to two nursing staff at a time. The enhanced training program was provided for each shift and required nursing personnel to identify the type of transfer and procedures required for each resident, and to demonstrate hands-on competency for each type of lifting equipment on actual residents with a range of disabilities. Training sessions with job specific content were provided to the nursing home administrator, nursing personnel, maintenance, and physical therapy staff. Training was conducted during new employee orientation, when there was a change in job assignment, and annually as part of continuing education. Maintenance staff received annual training on the maintenance of lifting equipment. A list of trained employees was maintained at each nursing home and certificates were provided to all trainees.

\section{Data sources}

Injuries, hours worked, and demographic data were supplied by the participating nursing homes for all nursing staff from l January 1995 through 31 December 2000.

\section{Injury records}

Data on worker injuries were examined from three different data systems: workers' compensation claims data, Occupational Safety and Health Administration (OSHA) 200 logs, and first reports of employee injury or illness to comprehensively evaluate the impact of the intervention on minor and severe injuries.

\section{Workers' compensation injury claims data}

These data included work related injuries requiring medical care or time away from work recorded by the company's workers' compensation reporting system, regardless of whether the claim was eventually accepted or rejected for compensation. Four nursing homes were in one state and two nursing homes were in an adjacent state with similar workers' compensation requirements. The only distinction was that employees in the two nursing homes had the right to select their own doctor or hospital for treatment.

Workers' compensation data also provided information about the medical and indemnity costs associated with each injury that led to a workers' compensation claim, which were updated in June 2003 for claims that continued to accrue costs beyond the end of the follow up period.

\section{OSHA 200 logs}

These data included injuries that resulted in days away from work, restricted work or transfer to another job, medical treatment beyond first aid, or loss of consciousness. OSHA $200 \operatorname{logs}$ also report the number of days lost by an employee due to incapacitation from an injury or the number of restricted days when a work related injury kept the employee from performing routine job functions.

\section{First reports of employee injury or illness}

In addition to workers' compensation and OSHA 200 logs, a detailed first report of employee injuries and illnesses was maintained by the safety department in each nursing home. These records included information on the hazardous exposure and injury event, the nature of the injury, the task being performed, and recommendations to prevent future occurrences.

\section{Human resources data}

Human resources records were obtained for all nursing employees and included data on productive hours worked per year (minus sick leave and vacation time), employee age, gender, job title, length of employment at the nursing home, usual shift worked, and employment status (full time, part time, or per diem). Job titles were used to classify employees 
as nursing or non-nursing. The nursing category included workers with jobs that regularly expose them to resident handling (such as certified nursing assistants, registered and licensed practical nurses, physical therapists, and restorative aides).

\section{Case definition}

Cases were defined as musculoskeletal injuries that occurred while lifting or moving a resident. Narrative information from injury reports were used to code the injury and define a case. The detail in the narrative descriptions allowed resident handling tasks to be coded (for example, "repositioning resident in bed", "assisting resident in/out of bed or chair", and "picking up resident who fell to the floor"). Generalized "sprain" or "strain" injuries not attributed to a specific source were also included as cases. Musculoskeletal injuries attributed to lifting objects (for example, beds, file cabinets, or garbage cans) were excluded. All other injuries (for example, slips and falls, struck by items, etc) among nursing staff were excluded as cases and non-case injury rates among nursing staff were analyzed as a reference group. The potential effect of the intervention on violent assault injuries to nursing personnel during resident handling tasks was examined separately.

\section{Statistical analysis}

Human resources records were merged with injury records for each employee to calculate rates. Poisson regression was used to compute rate ratios and $95 \%$ confidence intervals (CI) for assessing the relationship between injury rates and time period (pre-intervention and post-intervention), adjusting for potentially confounding covariates. ${ }^{11}{ }^{12}$ Potentially influential variables included nursing home (A, B, C, D, E, F), age group $(<25, \geqslant 25-<35, \geqslant 35-<45, \geqslant 45-<55, \geqslant 55$ years $)$, job tenure $(<1, \geqslant 1-<5, \geqslant 5-<10, \geqslant 10$ years $)$, gender, work status (full time, part time, per diem), and shift (day, evening, night, all) on injury rates (workers' compensation, OSHA, and first report data).

Separate models were run for each data source (workers' compensation claims, OSHA 200 logs, first reports of injury), for the resident handling and "all other injuries" groups. Because workers contributed multiple years of data, generalized estimating equations were used to control for withinworker correlation. ${ }^{13}$ The relationship between each of the covariates and injury was first assessed univariately. Score tests were used during univariate analysis to determine which of the covariates would be selected into the model. ${ }^{14-16}$ Covariates with $\mathrm{p}<0.25$ in univariate tests were entered into a final model with time period to assess pre and post significance of time period. ${ }^{17} Z$ tests using robust variance estimates were performed to test for significant differences in final adjusted rate ratios between the resident handling and "all other injuries" groups to determine if the injuries targeted by the intervention changed to a greater degree than non-targeted injuries in the pre-intervention to postintervention time periods. ${ }^{18}$

\section{RESULTS}

During the six year period January 1995 through December 2000, a dynamic cohort of 1728 nursing personnel worked a total of 3714700 work hours, with 1841236 hours worked in the pre-time and 1873549 hours worked in the post-time period. Of these 1728 nursing staff, $48 \%$ were present during only one year of data collection, $26 \%$ for two years, $9 \%$ for three years, $7 \%$ for four years, $5 \%$ for five years, and $5 \%$ for six years. The demographics of the nursing work force remained relatively unchanged during the pre-intervention and post-intervention time periods, such as percent of total workforce, age distribution, and percent female (table 1).
Table 1 Demographic characteristics of nursing staff pre-intervention and post-intervention

\begin{tabular}{lll}
\hline & $\begin{array}{l}\text { Pre-intervention } \\
\text { (1995-97) }\end{array}$ & $\begin{array}{l}\text { Post-intervention } \\
(1998-2000)\end{array}$ \\
\hline $\begin{array}{l}\text { \% Total workforce (based on } \\
\text { work hours) in nursing* }\end{array}$ & 52 & 52 \\
$\begin{array}{l}\text { Mean age (years) } \\
\text { \% By age group (years) }\end{array}$ & 37.7 & 38.5 \\
$<25$ & 11 & 9 \\
$\geqslant 25-<35$ & 26 & 21 \\
$\geqslant 35-<45$ & 31 & 34 \\
$\geqslant 45-<55$ & 20 & 22 \\
$\geqslant 55$ & 13 & 13 \\
\% Female of the nursing & 95 & 94 \\
workforce & & \\
\hline & *Certified nursing assistant, licensed practical nurses, and registered \\
nurses. &
\end{tabular}

\section{Resident handling injuries}

It was determined that nursing home, age, job tenure, gender, and work status were significant univariate predictors of resident handling workers' compensation injury claims rates; nursing home, age, job tenure, and gender were significant univariate predictors of OSHA injury rates; and nursing home, age, and job tenure were significant univariate predictors of resident handling injury rates reported in first report of injury.

After adjustment for these factors, workers' compensation resident handling injury claims rates decreased significantly in the post-intervention time period (table 2). Similarly, a significant reduction in resident handling injury rates derived from both the OSHA and first report of injury outcome measures decreased significantly in the post-intervention time period.

Reductions were observed in the frequency of employees reporting repeat injuries. During the pre-intervention period, 11 nursing staff filed more than one workers' compensation claim $(n=24)$; during the post-intervention period only three nursing staff filed repeat claims $(n=6)$.

\section{All other injuries reference group}

All other injuries experienced by nursing personnel were examined pre-intervention to post-intervention for comparison. The pre-intervention to post-intervention "all other injuries" workers' compensation claims rate was significantly reduced (rate ratio $=0.65,95 \%$ CI 0.47 to 0.90 ) after adjusting for covariates (nursing home, job tenure, sex, and work status). No significant reductions were found in the preintervention to post-intervention rates for "all other injuries" based on the first report of injury and OSHA 200 log outcome measures.

Since workers' compensation injury claims rates declined significantly pre-intervention to post-intervention for both resident handling and all other injury types, a Z test was performed to determine if there was a significant difference between the two rate ratios. Based on the $\mathrm{Z}$ test, the reduction in the resident handling injury rate was significantly greater $(Z=2.05, p<0.05)$ than the reduction in the "all other injuries" rate for workers' compensation claims. Figure 1 summarizes the pre-rate ratios to post-rate ratios for resident handling compared with "all other injuries" in nurses for the three injury data sources.

The intervention had a similar effect across subcategories of employee characteristics. Resident handling injury rates were down from pre-intervention to post-intervention across all nursing homes, all age groups (fig 2), all categories of job tenure (fig 3), and work status (fig 4). Declines were apparent in day and night shifts, but not the evening shift. Declines in female employees' injury rates were greater than 
Table 2 Resident handling injury workers' compensation claims, rate ratios showing change in pre-intervention to postintervention injury rates, adjusted for covariates

\begin{tabular}{|c|c|c|c|c|c|c|c|c|c|}
\hline \multirow[b]{2}{*}{ Time period } & \multicolumn{3}{|c|}{ Workers' compensation claims } & \multicolumn{3}{|l|}{ OSHA 200 logs } & \multicolumn{3}{|c|}{ First reports of employee injury } \\
\hline & $\begin{array}{l}\text { No of claims/ } \\
1000 \text { hours } \\
\text { (rate per } 100 \text { FTE) }\end{array}$ & $\begin{array}{l}\text { Rate } \\
\text { ratio }\end{array}$ & $95 \% \mathrm{Cl}$ & $\begin{array}{l}\text { No of claims/ } \\
1000 \text { hours } \\
\text { (rate per } 100 \mathrm{FTE} \text { ) }\end{array}$ & $\begin{array}{l}\text { Rate } \\
\text { ratio }\end{array}$ & $95 \% \mathrm{Cl}$ & $\begin{array}{l}\text { No of claims/ } \\
1000 \text { hours } \\
\text { (rate per } 100 \text { FTE) }\end{array}$ & $\begin{array}{l}\text { Rate } \\
\text { ratio }\end{array}$ & $95 \% \mathrm{Cl}$ \\
\hline $\begin{array}{l}\text { Pre-liffing } \\
\text { equipment } \\
\text { (1995-97) }\end{array}$ & $129 / 1841.2(14.0)$ & 1.0 & - & $124 / 1841.2(13.4)$ & 1.0 & - & $125 / 1052.1(23.7)$ & 1.0 & - \\
\hline $\begin{array}{l}\text { Post-lifting } \\
\text { equipment } \\
(1998-2000)\end{array}$ & $56 / 1873.5(5.9)$ & 0.39 & 0.29 to 0.55 & $69 / 1873.5(7.3)$ & 0.54 & 0.40 to 0.73 & $98 / 1383.6(14.1)$ & 0.65 & 0.50 to 0.86 \\
\hline
\end{tabular}

that of males, however this may be affected by the small number of claims $(n=2)$ generated by males in both the preintervention and post-intervention time periods. Workers' compensation injuries were reduced for all types of resident transfers; however, not all resident transferring tasks were equally impacted by the intervention. Table 3 shows the rate, number, and percent reduction of resident handling compensation claims pre-intervention and post-intervention by type of resident handling task.

\section{Assaults and violent acts}

A secondary hypothesis in this study examined if the use of mechanical lifting equipment were associated with a decline in injuries associated with resident assaults and violent acts towards nursing staff during resident handling tasks. The detail in the narrative incident descriptions made it possible to distinguish whether assaults and violent acts occurred during the course of a resident transfer. The data show that post-intervention resident handling assault rates were lower than pre-intervention resident handling assault rates. The rate of post-intervention assaults during resident transfers was down $72 \%, 50 \%$, and $30 \%$ based on workers' compensation, OSHA, and first reports of injury data, respectively (table 4).

\section{Lost and restricted workday analysis}

The rate of lost work day resident handling injuries declined significantly pre-intervention compared with post-intervention (5.8 to 2.0 lost work day injuries per 100 nursing

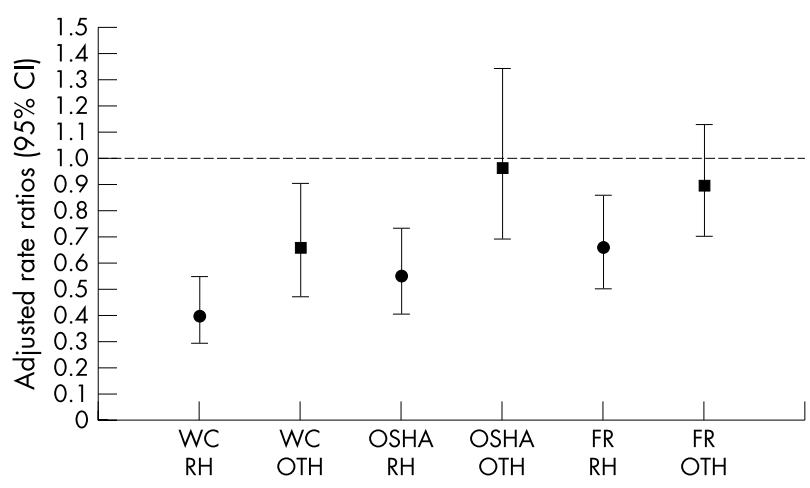

Figure 1 Adjusted rate ratios ( $95 \%$ confidence intervals) for preintervention to time periods. For workers' compensation claims (WC) both resident handling $(\mathrm{RH})$ and all other injury (OTH) rates declined significantly. The $\mathrm{RH}$ rate ratio was significantly lower than the OTH rate ratio $(Z=2.05, p<0.05)$. The OSHA $200 \log (\mathrm{OSHA})$ rate ratio for $\mathrm{RH}$ injuries declined significantly whereas the OTH rate did not show a significant decline. Similarly, the first report of employee injury (FR) rate declined significantly for $\mathrm{RH}$ injuries whereas the OTH rate did not show a significant decline.

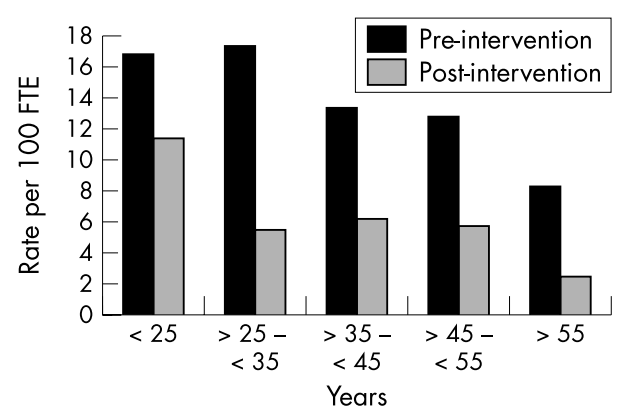

Figure 2 Unadjusted pre-intervention and post-intervention resident handling workers' compensation injury claim rates by age category (FTE, full time equivalents).

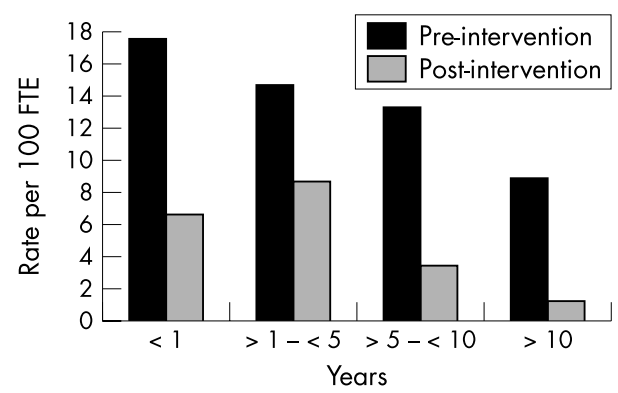

Figure 3 Unadjusted pre-intervention and post-intervention resident handling workers' compensation injury claim rates by job tenure category (FTE, full time equivalents).

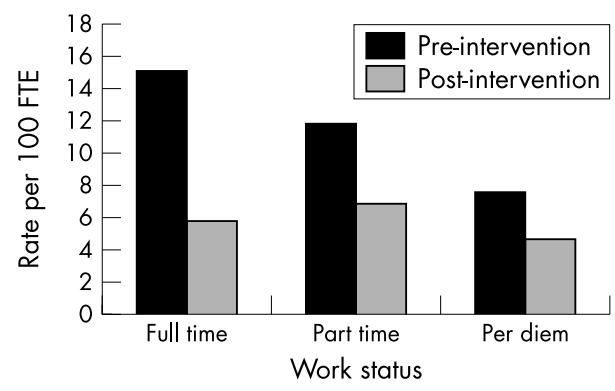

Figure 4 Unadjusted pre-intervention and post-intervention resident handling workers' compensation injury claim rates by work status category (FTE, full time equivalents).

personnel, rate ratio $=0.34,95 \%$ CI 0.20 to 0.60$)$. A total of 488 work days were lost due to resident handling injury preintervention compared with 229 days post-intervention. The rate of restricted work day resident handling injuries also 


\begin{tabular}{|c|c|c|c|}
\hline Resident handling task & $\begin{array}{l}\text { Rate per } 100 \mathrm{FTE}(\mathrm{No}) \text { of } \\
\text { pre-intervention Injuries }\end{array}$ & $\begin{array}{l}\text { Rate per } 100 \mathrm{FTE}(\mathrm{No}) \text { of } \\
\text { post-intervention Injuries }\end{array}$ & \% Reduction \\
\hline $\begin{array}{l}\text { In/out of bed, bed to chair, chair } \\
\text { to bed }\end{array}$ & 3.80 (35) & $1.49(14)$ & 61 \\
\hline Repositioning in bed & 1.85 (17) & $1.17(11)$ & 36 \\
\hline Turning/rolling resident & $2.17(20)$ & $0.85(8)$ & 61 \\
\hline Breaking residents fall & $1.74(16)$ & $1.07(10)$ & 39 \\
\hline Toileting & $0.54(5)$ & $0.32(3)$ & 41 \\
\hline Liffing resident off the floor & $0.54(5)$ & $0.32(3)$ & 41 \\
\hline $\begin{array}{l}\text { Resident transfer, not otherwise } \\
\text { classified }\end{array}$ & $2.61(24)$ & $0.64(6)$ & 76 \\
\hline Sprain/strain, not otherwise classified & $0.76(7)$ & $0.11(1)$ & 86 \\
\hline
\end{tabular}

declined significantly, from 9.3 to 5.7 restricted work days per 100 nursing personnel (rate ratio $=0.62,95 \%$ CI 0.44 to 0.87 ). A total of 1314 days of restricted work activity occurred preintervention compared with 687 post-intervention.

\section{Cost benefit analysis}

Costs and benefits attributable to this intervention were assessed pre-intervention and post-intervention. The hospital corporation in this study is self insured, therefore the cost benefit analysis assumes that savings in workers' compensation medical and indemnity payments are recovered immediately, rather than a reduction in insurance premiums in future years. Information obtained from the hospital corporation indicated that the total capital investment for equipment purchases was $\$ 143556$ and an estimated $\$ 15000$ was invested in employee training. The direct workers' compensation expense for the 129 employee injuries related to resident handling during the pre-intervention period was $\$ 441670.11$. The total workers' compensation expenses incurred for the 56 employee injuries related to resident handling during the post-intervention period were $\$ 277$ 060.71. Given the benefit of the direct savings of $\$ 164609.40$ in workers' compensation costs during the postintervention period and the $\$ 158556$ capital expenses to purchase lifting equipment and provide worker training, the reduction in workers' compensation expenses recovered the initial investment in slightly less than three years. The return on investment is shorter if savings in indirect costs are considered (for example, lost wages, cost of hiring and retraining workers, etc).

\section{DISCUSSION}

This intervention trial included 1728 different nursing employees over a six year period. Controlling for multiple factors, strong evidence was found to support an intervention consisting of mechanical resident lifting equipment, worker training on the proper use of the lifts, and a zero lift policy as a protective measure for preventing staff injuries associated with resident handling. This study utilized multiple sources of injury data (workers' compensation injury claims, OSHA $200 \operatorname{logs}$, and first reports of employee injury) to examine the impact of the prevention program on minor and severe injuries. Resident handling injury rates were significantly reduced from the pre-intervention to post-intervention time period for all three injury data sources. The largest reductions occurred among the more serious injuries that resulted in workers' compensation claims. The data also suggest that the effect of the mechanical lifting equipment intervention was beneficial for all nursing homes, for workers in all age groups, lengths of tenure, and for full time, part time, and per diem staff.

We did not have the option of randomly assigning the intervention because the intervention was implemented in all six nursing homes owned by the non-profit health care system. All other injuries in nursing personnel were used as a reference group; it was anticipated that injuries targeted by the intervention would decline whereas non-targeted injuries would not.

All other injuries either showed no decline (OSHA 200 logs and first reports) from the pre-intervention to post-intervention time period, or showed significant (workers' compensation), but smaller, declines than were found in resident handling injuries. This suggests that a portion of the reduction in resident handling injuries seen after the intervention may have been due to external factors.

Additionally, this study documented a decline in injuries associated with resident assaults and violent acts towards nursing staff during resident handling tasks. Other studies have shown that using mechanical equipment to lift residents increases a resident's comfort and feeling of security when compared with manual methods..$^{7-9}$ Manually lifting residents under the axilla can be quite painful for residents and exert excessive forces on a resident's shoulder. ${ }^{19}$ The physical separation between the caregiver and the resident afforded by the use of the lift, particularly those with a known history of violence, could also explain the reduction in assaults on caregivers while using mechanical lifts.

Numerous studies document the difficulties and physical consequences of manually moving patients and laboratory studies have documented the success of mechanical lifts in applied settings for reducing strain and injuries on nurses

Table 4 Assaults and violent acts during resident handling

\begin{tabular}{llll}
\hline Data source & $\begin{array}{l}\text { Rate (No) of pre- } \\
\text { intervention assault } \\
\text { injuries per 100 FTE }\end{array}$ & $\begin{array}{l}\text { Rate (No) of post- } \\
\text { intervention assault } \\
\text { injuries per 100 FTE }\end{array}$ & \% Reduction \\
\hline Workers' compensation claims & $0.76(7)$ & $0.21(2)$ & $72 \%$ \\
OSHA 200 logs & $0.65(6)$ & $0.32(3)$ & $50 \%$ \\
First report of employee injury or illness & $5.32(28)$ & $3.75(26)$ & $30 \%$ \\
\hline FTE, full time equivalents. & & & \\
\hline
\end{tabular}




\section{Key points}

- These results demonstrated that a safe resident handling and movement program significantly reduced the rate, severity, and cost of injuries to caregivers associated with lifting and moving residents. Lost work day and restricted work day injury rates were significantly reduced as was the frequency of employees who reported repeat injuries.

- The safe resident handling and movement program reduced injuries in all nursing homes, for caregivers in all age groups, lengths of tenure, and for full time, part time, and per diem staff.

- Assaults and violent acts by residents towards caregivers declined after the safe resident handling and movement program was implemented.

- The reduction in workers' compensation injury claims expenses recovered the initial capital investment in equipment and training in slightly less than three years.

and persons responsible for moving patients. This study and other field studies provide evidence that replacing manual lifting with modern, battery powered mechanical lifts can be a highly effective preventive measure ${ }^{90-24}$ and provide support for the recently issued OSHA Guidelines for the Prevention of Musculoskeletal Disorders in Nursing Homes. ${ }^{25}$

Barriers to purchasing lifting equipment may include cost, concerns about resident comfort and security, and the time required to use the equipment. This study confirms findings from other studies ${ }^{21}{ }^{23}$ and demonstrates that it is possible to overcome these barriers, achieve staff buy-in and compliance with a policy requiring the use of lifting equipment, and reduce injury rates and associated costs. This study showed that the reduction in workers' compensation injury claims expenses effectively recovered the initial capital investment in equipment and training in slightly less than three years, and potentially more quickly if indirect costs are considered.

\section{ACKNOWLEDGEMENTS}

We acknowledge the efforts of David K Hilling and Scott A Hendricks, MS, for programming and analytical support, respectively; Bernice D Owen, PhD, and Ziqing Zhuang, PhD, for scientific contributions; Roger Jensen, PhD, Guy Fragala, PhD, Linda Frederick, PhD, James T Wassell, PhD, and Audrey Nelson, PhD, RN, FAAN for critical review.

\section{Authors' affiliations}

J W Collins, J Bell, Centers for Disease Control and Prevention, National Institute for Occupational Safety and Health, Division of Safety Research, Morgantown, West Virginia, USA
L Wolf, BJC Health System, BJC Corporate Health Services, St Lovis, Missouri, USA

B Evanoff, Washington University School of Medicine, St Louis, Missouri, USA

\section{REFERENCES}

1 Anonymous. The nurse's load (editorial). Lancet 1965;ii:422-3.

2 Guo HR, Tanaka S, Cameron LL, et al. Back pain among workers in the United States: national estimates and workers at high risk. Am J Ind Med 1995;28:591-602.

3 US Department of Labor, Bureau of Labor Statistics. Total recordable occupational injury and illness cases in nursing and personal care facilities. 2001. Available at: http://www.bls.gov/data/home.htm (accessibility verified 7 August 2003).

4 US Department of Labor, Bureau of Labor Statistics. Employed persons by detailed occupation, sex, race, and Hispanic origin, 2002. Available at: http://www.bls.gov/cps/cpsaat1 1 .pdf (accessibility verified 4 September 2003).

5 Garg A, Owen BD, Carlson B. An ergonomic evaluation of nursing assistants' job in a nursing home. Ergonomics 1992;35:979-95.

6 Buerhaus P, Staiger D, Auerbach D. Implications of a rapidly aging nursing workforce. JAMA 2000;283:2948-54.

7 Zhuang Z, Stobbe TJ, Hsiao H, et al. Biomechanical evaluation of assistive devices for transferring residents. Appl Ergon 1999;30:285-94.

8 Zhuang Z, Stobbe TJ, Collins JW, et al. Psychophysical assessment of assistive devices for transferring patients/residents. Appl Ergon 2000;31:35-44.

9 Garg A, Owen B. Reducing back stress to nursing personnel: an ergonomic intervention in a nursing home. Ergonomics 1992;35:1353-75.

10 Collins JW, Owen BD. NIOSH research initiatives to prevent back injuries to nursing assistants, aides, and orderlies in nursing homes. Am J Ind Med 1996;29:421-4.

11 Frome EL. The analysis of rates using Poisson regression models. Biometrics 1983:39:665-74.

12 SAS Institute Inc. The GENMOD procedure. SAS technical report. Cary, NC: SAS Institute Inc, 1993:243.

13 Liang KY, Seger SL. Longitudinal data analysis using generalized linear models. Biometrika 1986;73:13-22.

14 Rotnitzky A, Jewell NP. Hypothesis testing of regression parameters in semiparametric generalized linear model for cluster correlated data. Biometrika 1990;77:485-97.

15 Boos D. On generalized score tests. The American Statistician 1992;46:327-33.

16 SAS Institute Inc. SAS OnlineDoc. Version 8, February 2000. Copyright (ن)2000, 2000.

17 Hosmer DW, Lemeshow S. Applied logistic regression. New York: John Wiley, 1989

18 Dowdy S, Weardon S. Statistics for research. 2nd Ed. New York: John Wiley, 1985.

19 Owen BD. Back stress isn't part of the job. American Journal of Nursing 1993;2:1-3.

20 Fragala G. Ergonomics: how to contain on-the-job injuries in health care Joint Commission on Accreditation of Healthcare Organizations, 1999. (ISBN 086688-417-3.)

21 Garg A. Long-term effectiveness of "zero-lift program" in seven nursing homes and one hospital. Contract No U60/CCU512089-02. Centers for Disease Control and Prevention, National Institute for Occupational Safety and Health, 16 August, 1999.

22 Tiesman HM, Nelson AL, Charney W, et al. Effectiveness of a ceiling-mounted patient lift system in reducing occupational injuries in long term care. Journal of Healthcare Safety 2003; 1(1):34-40.

23 Nelson AL, Lloyd J, Menzel N, et al. Preventing nursing back injuries: redesigning patient handling tasks. AAOHN Journal 2003;51:126-34.

24 Evanoff $B$, Wolf $L$, Aton $E$, et al. Reduction in injury rates in nursing personnel through introduction of mechanical lifts in the workplace. Am J Ind Med 2003;44:451-7.

25 US Department of Labor, Occupational Safety and Health Administration. Guidelines for nursing homes-ergonomics for the prevention of musculoskeletal disorders. OSHA 3182, 2003. Available at: http:// www.osha.gov/ergonomics/guidelines/nursinghome/index.html. 